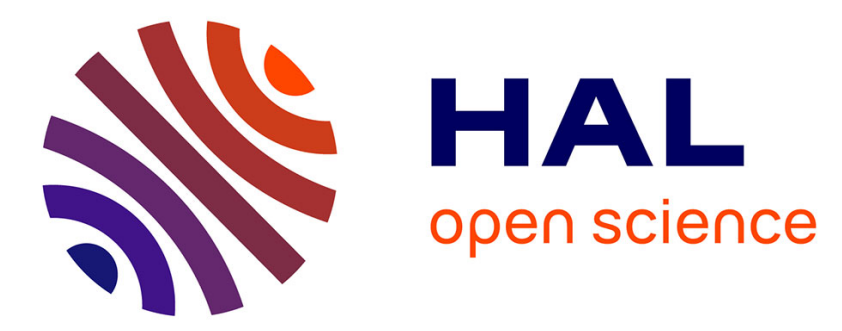

\title{
Fluid-flow measurements in low permeability media with high pressure gradients using neutron imaging: Application to concrete
}

\author{
Mohamad Yehya, Edward Ando, Frédéric Dufour, Alessandro Tengattini
}

\section{To cite this version:}

Mohamad Yehya, Edward Ando, Frédéric Dufour, Alessandro Tengattini. Fluid-flow measurements in low permeability media with high pressure gradients using neutron imaging: Application to concrete. Nuclear Instruments and Methods in Physics Research Section A: Accelerators, Spectrometers, Detectors and Associated Equipment, 2018, 890, pp.35-42. 10.1016/j.nima.2018.02.039 . hal-01994211

\section{HAL Id: hal-01994211 \\ https://hal.univ-grenoble-alpes.fr/hal-01994211}

Submitted on 25 Jan 2019

HAL is a multi-disciplinary open access archive for the deposit and dissemination of scientific research documents, whether they are published or not. The documents may come from teaching and research institutions in France or abroad, or from public or private research centers.
L'archive ouverte pluridisciplinaire HAL, est destinée au dépôt et à la diffusion de documents scientifiques de niveau recherche, publiés ou non, émanant des établissements d'enseignement et de recherche français ou étrangers, des laboratoires publics ou privés. 


\title{
Fluid-flow measurements in low permeability media with high pressure gradients using neutron imaging: Application to concrete
}

\author{
Mohamad YEHYA ${ }^{\mathrm{a}, \mathrm{b},{ }^{*}, \text { Edward ANDÒ }}{ }^{, *}$, Frédéric DUFOUR ${ }^{\mathrm{a}, \mathrm{c}}$, and Alessandro \\ TENGATTINI ${ }^{\mathrm{a}, \mathrm{d}}$ \\ ${ }^{a}$ Univ. Grenoble Alpes, CNRS, Grenoble INP† 3SR, F-38000 Grenoble, France \\ ${ }^{\mathrm{b}}$ Grenoble INP Partnership Foundation, Chair PERENITI - EDF, Grenoble, France \\ ${ }^{\mathrm{c}}$ Chairholder, Chair PERENITI (EDF SEPTEN/DTG/CIH), Grenoble, France \\ dInstitut Laue-Langevin, 71 Avenue des Martyrs, 38000 Grenoble
}

\begin{abstract}
This article focuses on a new experimental apparatus for investigating fluid flow under high pressure gradients within low-permeability porous media by means of neutron imaging. A titanium Hassler cell which optimises neutron transparency while allowing high pressure confinement (up to $50 \mathrm{MPa}$ ) and injection is designed for this purpose and presented here. This contribution focuses on the development of the proposed methodology thanks to some preliminary results obtained using a new neutron imaging facility named NeXT on the D50 beamline at the Institute Laue Langevin (Grenoble). The preliminary test was conducted by injecting normal water into concrete sample prepared and saturated with heavy water to take advantage of the isotope sensitivity of neutrons. The front between these two types of water is tracked in space and time with a combination of neutron radiography and tomography.
\end{abstract}

Keywords: fluid flow, neutron imaging, porous media, heavy water, normal water

\section{INTRODUCTION}

The investigation of fluid flow in porous media, and specifically full field measurements of local processes, is of significant interest for many industrial and environmental applications such as the disposal of hazardous waste, water evaporation and infiltration in soil. Local measurements of fluid flow in 3D present a convenient way to access a permeability field in different engineering porous media (such as concrete, bricks and ceramics, rocks, fuel cells etc.). The ability to deduce a permeability field has important repercussions on the development of better hydraulic material models (which can be thermo-, hydro-mechanically coupled).

In the case of an incompressible fluid (water for specific pressures for instance), under laminar flow condition, the permeability of the medium can be directly obtained by applying Darcy's law. The concept of permeability defined by Darcy's law, expresses, on a macroscopic scale, the physics of the flow of a viscous Newtonian fluid (the forces due to the viscosity dominate inertial forces) at the scale of pores. In the literature, many authors have made gas- or water-permeability measurements on different materials such as concrete, ${ }^{1-3}$ mortars, ${ }^{4}$ rocks,${ }^{5}$ etc. . Standard laboratory experiments consist in measuring flow from one end of a test specimen to the other without full knowledge of how the fluid flows in the sample. The current measurements only allow for the identification of average characteristics where extrapolation to the engineering scale (power stations and dams for concrete, rock mass for $\mathrm{CO}_{2}$ reservoir, oil pumping, shale gas, etc.) is necessary. In the case of homogeneous materials and an assumed homogeneous flow, this can be sufficient. However, a large number of complex heterogeneous materials are routinely used in engineering practice today (concrete and reinforced concrete are an excellent example), whose permeability is locally inhomogeneous. In the case, the understanding of the details of fluid

\footnotetext{
$\dagger$ Institute of Engineering Univ. Grenoble Alpes

* Corresponding authors.

E-mail addresses: mohamad.yehya@3sr-grenoble.fr (M. Yehya), edward.ando@3sr-grenoble.fr (E. Andò).
} 
flow are pivotal because of the implications on the preferential paths of damage and weathering which, in turn affects durability and containment.

The literature reports several works investigating the porosity, the moisture content and the sorptivity of a porous specimen such as sandstone,${ }^{6,7}$ concrete, ${ }^{8-11}$ porous asphalt, ${ }^{12}$ clay rock ${ }^{19}$ using neutron radiography. Most of the studies, if not all, focus on the rising water front by imbibition so that a local velocity field can be obtained by assessing the displacement of the front in time which is a product of the competition between capillary suction driving and the medium's permeability. This competition makes the acquired data difficult to analyse. In order to get permeability-dominated flow directly, a saturated and fluid-pressure controlled test is recommended. De Beer and Middleton ${ }^{6}$ were the first to use neutron imaging for two-phase fluid flow through an oil bearing rock inside a Hassler high-pressure apparatus in order to reproduce deep reservoir pressure conditions. In their experiment, they injected $\mathrm{D}_{2} \mathrm{O}$ through a sandstone sample under a pressure of $0.02 \mathrm{MPa}$ causing oil to move at $3 \mathrm{~cm}^{3} / \mathrm{min}$. This important step for measuring permeability-dominated flow directly is significantly extended in this work to higher pressures allowing lower permeability materials to be tackled.

Quantification and analysis of the spatial distribution of fluid flow in porous media is to this day a major scientific challenge. In order to investigate low permeability porous media (Concrete has an intrinsic permeability of around $\left.10^{-17} \mathrm{~m}^{2}\right)^{15}$ in reasonable experimental time (hours not days), a large pressure gradient is required. For example, for a material like concrete cited above (assuming no dependence of permeability on mean stress), by applying Darcy's law with a pressure gradient of $40 \mathrm{MPa}$, a water front would cross the sample of $7 \mathrm{~cm}$ height in around 200 minutes. Consequently, a higher confining pressure should be applied to avoid the damage by the fluid driving pressure. Making a measurement of fluid flow in saturated conditions will allow the geometric complexities inherent with capillary rise to be avoided.

This paper proposes a full-field imaging method, using neutron imaging, to quantify fluid flow within a porous specimen, and applies this technique to the very challenging case of concrete (low permeability) in saturated conditions (where no obvious flow front is normally observed using regular imaging techniques).

The aim of this paper is to show the design of the new experimental set-up that allows hydraulic flow through cylindrical samples to be monitored under $50 \mathrm{MPa}$ confinement using neutron radiography and tomography.

\section{NEUTRON IMAGING}

Neutron radiography has shown in previous studies its sensitivity to fluids with high hydrogen content (especially water) ${ }^{15}$ and multiphase fluid flow ${ }^{16}$ in a specimen. It is a powerful tool in the determination of the hydraulic behaviour in geomaterials and concrete compared to x-rays (which itself is better suited for studying the solid skeleton $\left.{ }^{17}\right)$.

The essential difference between $\mathrm{x}$-rays and neutrons is that $\mathrm{x}$-rays interact with the electron clouds of the atom and their attenuation scales with the atomic number $\mathrm{Z}$ (heavier atoms attenuates more), whereas the neutrons interact with the nuclei and their attenuation (and scattering) does not follow an intuitive pattern across the periodic table, as hinted by Figure 1. The difference between the two interaction mechanisms gives a difference in contrast when both types of radiation are used for tomography. In this work, all neutron imaging is performed on NeXT-Grenoble, the imaging instrument on D50 at the ILL. ${ }^{14}$ Figure 2 shows two horizontal slices of a $\mathrm{D}_{2} \mathrm{O}$ saturated cylindrical concrete sample of $7 \mathrm{~cm}$ in diameter using both techniques*. Although the image is sharper with x-rays since the resolution is higher, the x-ray attenuation of the cement matrix and the aggregates is very close meaning that they are difficult to distinguish. While with neutrons, we can visualize aggregates, cement paste and pores but with lower resolution.

Some heavy elements (such as titanium and aluminium) are relatively transparent to neutrons, which allows testing apparatus capable of withstanding high pressures to be used to perform in-situ neutron imaging tests. Unlike x-rays, neutrons can be highly sensitive to some light elements such as hydrogen and lithium and are furthermore isotope-sensitive. An excellent example of isotope sensitivity is between hydrogen $(\mathrm{H})$ which is highly attenuating and deuterium $(\mathrm{D}$, i.e., an $\mathrm{H}$ atom containing a neutron) which attenuates significantly fewer

${ }^{*}$ The x-ray tomography was done on Laboratoire 3SR's micro-focus x-ray scanner and Neutron tomography was done on NeXT-Grenoble. Please note: NeXT-Grenoble will soon be equipped with its own micro-focus x-ray scanner. 


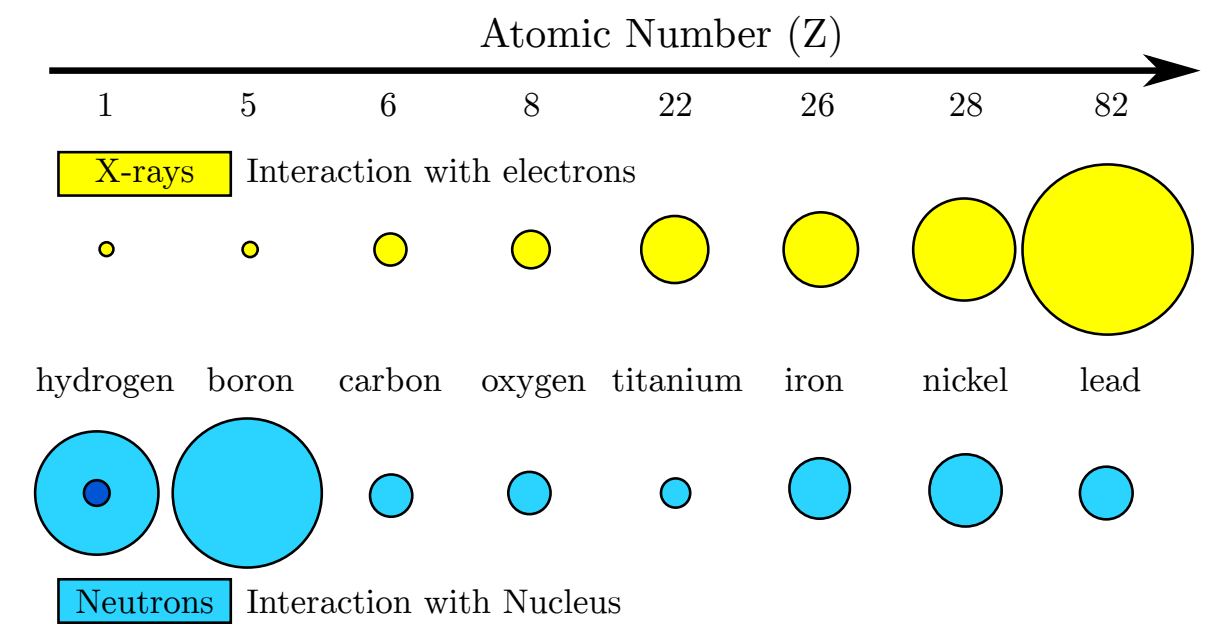

Figure 1. Difference between neutron and x-ray attenuation for some elements. Adapted from: http: //centrin.net.id/ nslbatan/, https://www.psi.ch/niag/comparison-to-x-ray, http://nmi3.eu/news-and-media/ neutron-imaging-past-present-and-future.html

neutrons. Consequently, the significant contrast in neutron imaging between water $\left(\mathrm{H}_{2} \mathrm{O}\right)$ and heavy water $\left(\mathrm{D}_{2} \mathrm{O}\right)$ (liquids which are otherwise hydraulically similar ${ }^{\dagger}$ ) allows a fluid front in saturated conditions to be visualised with ease.

\section{EXPERIMENTAL SETUP AND MEASURES}

\subsection{Neutron Hassler Cell}

Figure 3 and Table 1 show the original design and the principal characteristics of the neutron Hassler cell. It was optimised to accommodate cylindrical samples (easy to pour or core) which also simplifies the acquisition of in-situ tomographies and furthermore takes advantage of the large availability of tubular membranes.

\begin{tabular}{|c|c|}
\hline Material & Titanium; TA6V \\
\hline Confining pressure & up to $50 \mathrm{MPa}$ \\
\hline Temperature & $10^{\circ} \mathrm{C}$ to $150^{\circ} \mathrm{C}$ \\
\hline Internal diameter of the sample & $70 \mathrm{~mm}$ \\
\hline Length of the sample & variable, up to $200 \mathrm{~mm}$ \\
\hline Fluid content & liquid \\
\hline Confining volume & $325 \mathrm{ml}$ \\
\hline
\end{tabular}

Table 1. General characteristics of the neutron Hassler cell.

In order to percolate the water along the axis of the cylindrical sample, a fluid injection from one side of the specimen is required, together with a pressure gradient to drive the flow. The exit pressure used here is atmospheric pressure, even though with the proposed apparatus any back-pressure can be imposed. To prevent

\footnotetext{
${ }^{\dagger}$ The difference in terms of neutron attenuation is due to the neutron capture cross-section of deuterium $\sigma=0.00046$ barn, almost 1000 times lower than the one of ordinary water. http://akilia.alwaysdata.net/scf_old/ produit-du-jour/eau-lourde.html

In terms of mechanical properties, $\mathrm{D}_{2} \mathrm{O}$ is $10.6 \%$ denser and $20 \%$ more viscous than $\mathrm{H}_{2} \mathrm{O}$ at a temperature of $20^{\circ} \mathrm{C}$. However, the other properties (surface tension, boiling point, etc.) are quite similar. https://en.wikipedia.org/wiki/ Heavy_water Note that these two can mix and often there are even hydrogen/deuterium exchanges that lead to a semiheavy water (HDO). Nonetheless this process is sufficiently slow compared to the time of the test so it can be neglected.
} 

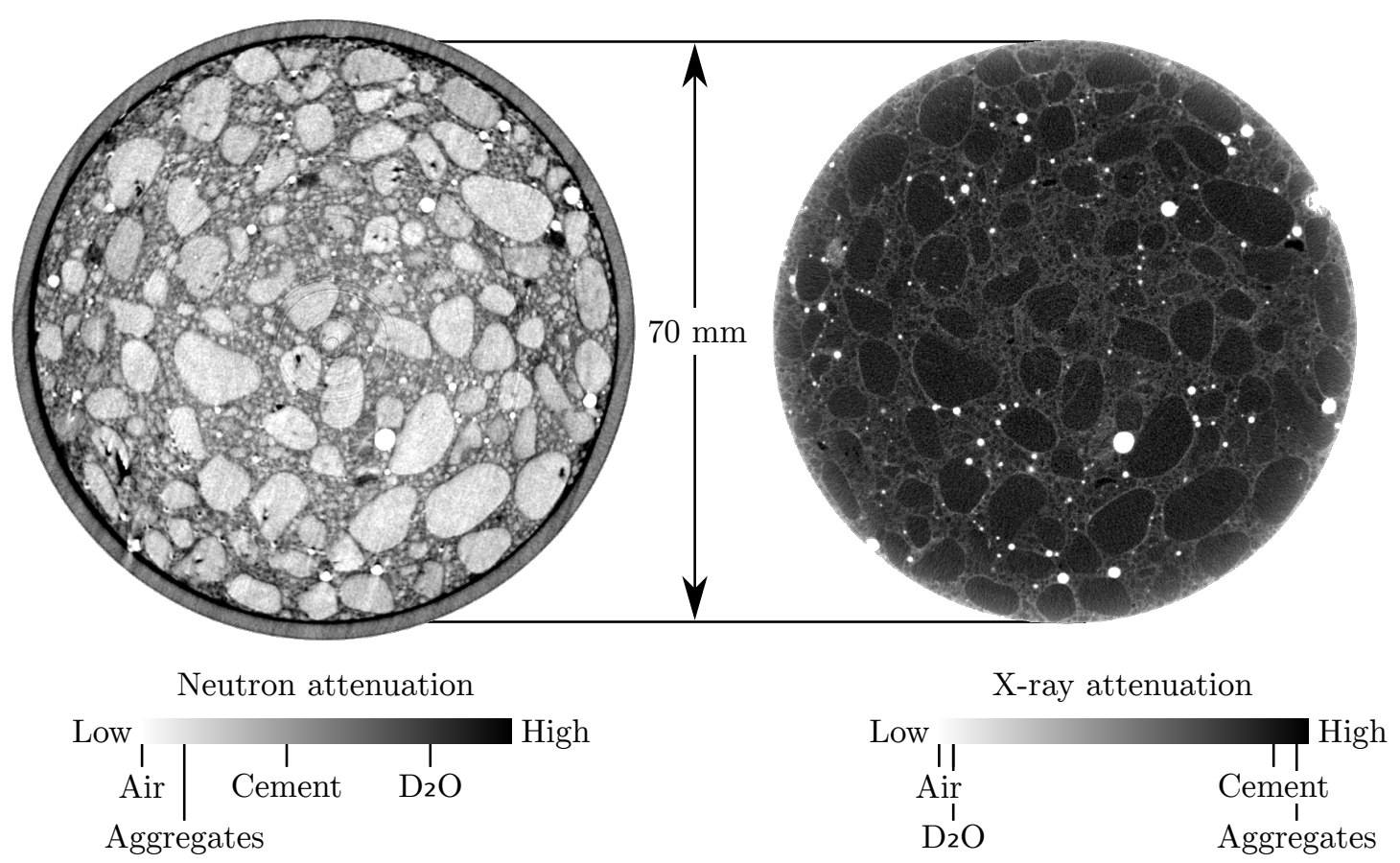

Figure 2. A tomography of a cylindrical concrete sample of $7 \mathrm{~cm}$ in diameter using neutrons (left) and x-rays (right).

leaking on the radial edges of the specimen and to prevent the internal damage of the material due to internal pressurization, a confining pressure greater than the injection pressure should be applied on the membrane that covers the sample. One standard ${ }^{13}$ suggests for example a confining pressure at least 1.25 times the injection pressure, as well as limiting the confinement to one-half of the uniaxiam compressive strength of the concrete.

To obtain a water flow speed adapted to the imaging requirements (i.e., fast enough to maintain scanning times reasonable), low permeability materials require a large pressure gradient, and therefore a large confinement pressure. This in turn requires strong materials with low neutron attenuation. The AG3 aluminium alloy is an obvious choice for neutron attenuation but a cell respecting safety standards could not be designed, since this would require very large cell walls which, by increasing the sample-detector distance would severely affect the resolution of the system. ${ }^{18}$ On the other hand, the titanium alloy (TA6V) that contains almost $90 \%$ of pure titanium, $6 \%$ of Aluminium and $4 \%$ of Vanadium, attenuates relatively few neutrons due to the small attenuation of its elements. It has also a good compromise between mechanical strength and toughness in addition to its excellent resistance to corrosion. For these reasons, the body of the cell is chosen to be made by TA6V. Given the very high strength of this alloy $(100 \mathrm{MPa})$, this cell can withstand a high confinement pressure for a minimum thickness. In this case, a confinement up to $50 \mathrm{MPa}$ can be achieved with a thickness of TA6V of $19.5 \mathrm{~mm}$.

To impose such confining pressures an incompressible liquid is required for safety reasons. In the proposed design $\mathrm{D}_{2} \mathrm{O}$ is selected as a confining fluid to minimise the overall attenuation of the apparatus. To further reduce attenuation, the volume of confining fluid is minimised, which also reduces the cost of each test (at the time of writing $\mathrm{D}_{2} \mathrm{O}$ with a purity of $99.8 \%$ is sourced at around $1000 € / \mathrm{l}$ ). Total confining volume of $325 \mathrm{~cm}^{3}$ will be needed for a sample of $200 \mathrm{~mm}$ length. A cylindrical sample of $70 \mathrm{~mm}$ in diameter can be tested in this cell. The length of this sample can vary between 100 and $200 \mathrm{~mm}$ thanks to a movable shutter - labelled 8 in Figure 3. Shorter samples can be tested also by adding cylindrical shims at the ends of the specimen. In 

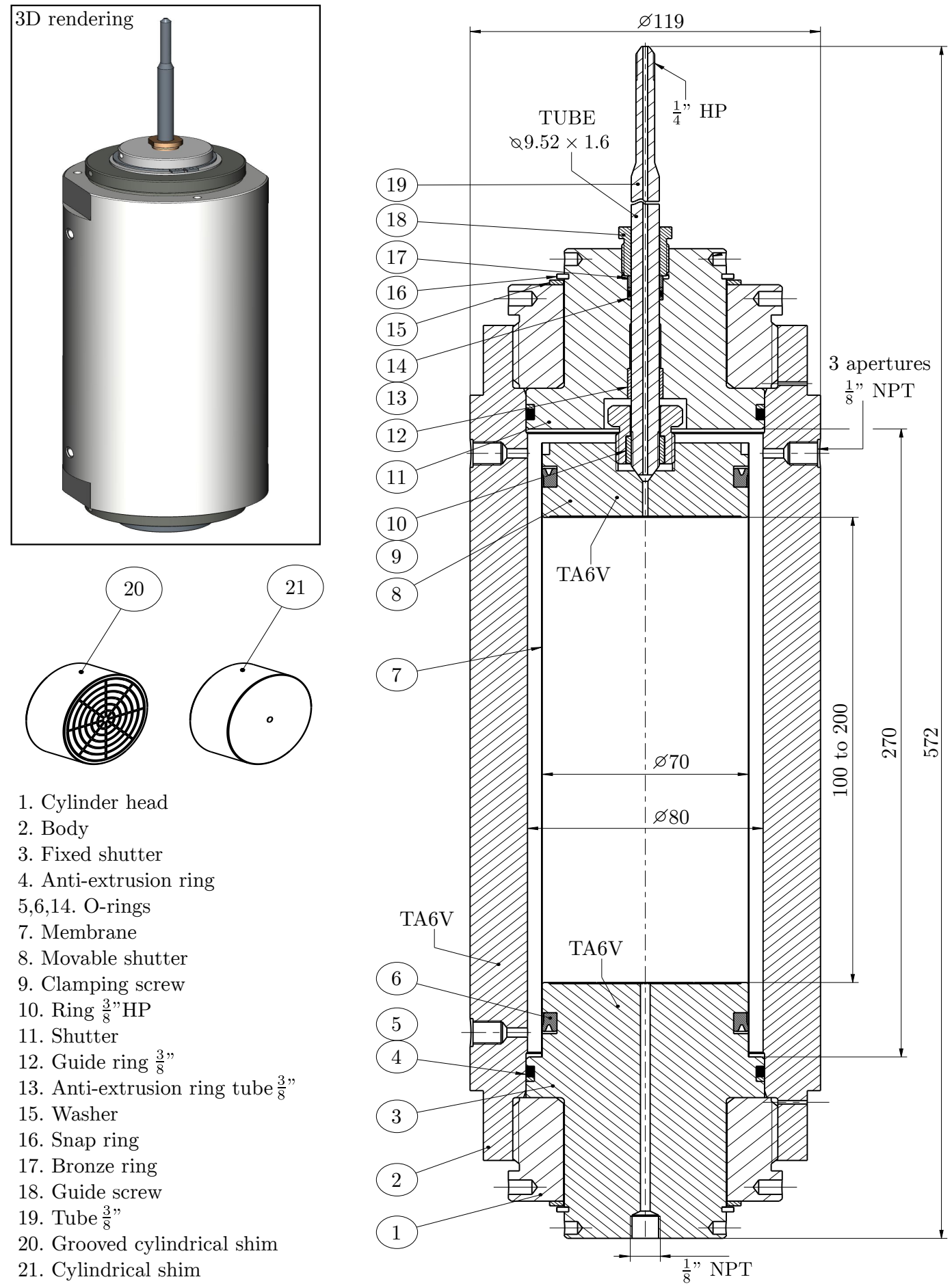

1. Cylinder head

2. Body

3. Fixed shutter

4. Anti-extrusion ring

$5,6,14$. O-rings

7. Membrane

8. Movable shutter

9. Clamping screw

10. Ring $\frac{3}{8}$ "HP

11. Shutter

12. Guide ring $\frac{3}{8} "$

13. Anti-extrusion ring tube $\frac{3}{8}$ "

15. Washer

16. Snap ring

17. Bronze ring

18. Guide screw

19. Tube $\frac{3}{8}$ "

20. Grooved cylindrical shim

21. Cylindrical shim

Figure 3. Technical drawing of the neutron Hassler cell. (Top Industrie - France)

addition, a bespoke circular base has been designed to set the cell on the existing rotation stage in the beamline and to have the possibility to rotate it and make tomographies in the most repeatable conditions.

The sample is encased within a special membrane to prevent flow along the edges (see section 3.2), after 
which it is placed and connected to one end of the cell, specifically the fixed shutter (3 in Figure 3 ), which is equipped with $1 / 8$ " nozzles that give access to both the confinement chamber as well as the sample. Thereafter, the cell walls (a filleted hollow cylinder) are screwed on this first base. Finally, the remaining base, which is equipped has the same fittings as the opposite end, is added to the system. It is at this point straightforward to add the confinement fluid, impose the desired pressure and start injection into the pore space of the specimen.

\subsection{Membranes}

In order to seal the sample during the experiment and to prevent penetration of the confining fluid, a membrane is necessary. The imposition of the high confinement pressure requires a membrane with good mechanical resistance, while being sufficiently flexible to adapt itself to the external shape of the specimen and as little neutron-attenuating as possible.

Three membranes were tested with a concrete sample under a pressure of $50 \mathrm{MPa}$ in order to choose the most suitable (see Figure 4 \& Table 2 ).

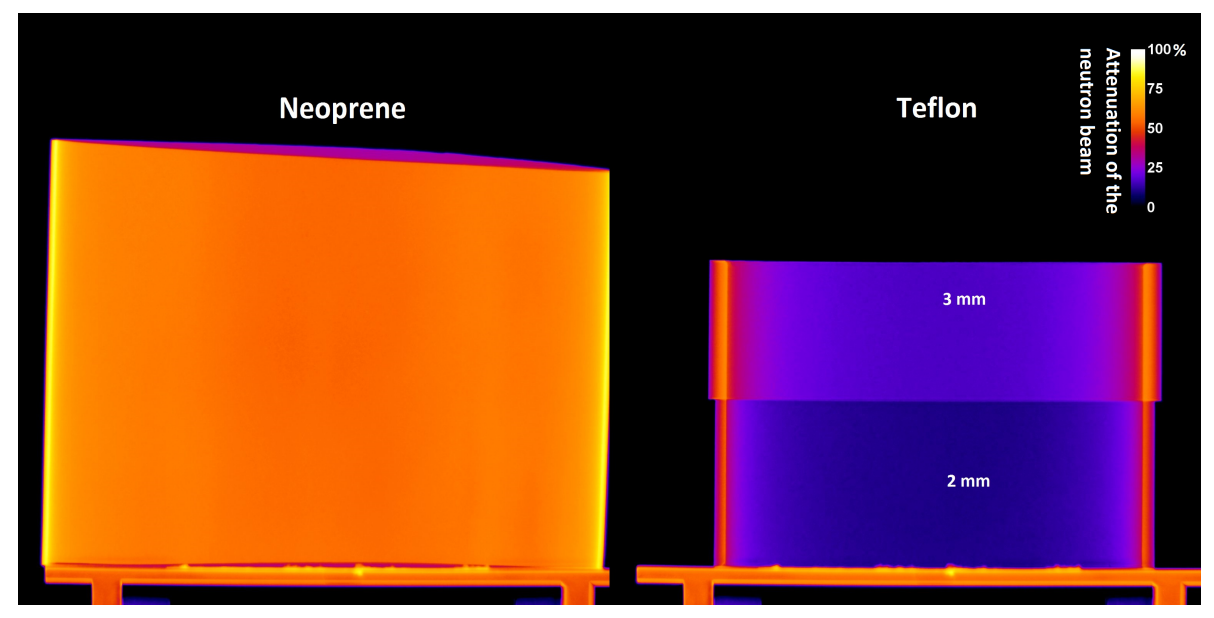

Figure 4. Neutron attenuation of the Neoprene and Teflon membranes

\begin{tabular}{|c|c|c|}
\hline Membrane & Neutron attenuation & $\begin{array}{c}\text { Resistance of the } \\
\text { membrane under } 50 \\
\text { MPa confining } \\
\text { pressure }\end{array}$ \\
\hline Aluminum $0.5 \mathrm{~mm}$ & $\sim 1 \%$ (calculated) & NO \\
\hline Teflon $2-3 \mathrm{~mm}$ & $10 \%-16 \%$ & YES \\
\hline Neoprene $0.5 \mathrm{~mm}$ & $55 \%$ & YES \\
\hline
\end{tabular}

Table 2. Mechanical resistance and attenuation of the membranes.

From an imaging point of view, the pure aluminium membrane is transparent to neutrons but it has not been possible to increase its thickness in order to not lose flexibility for the implementation. The tested aluminium membrane did not resist more than $20 \mathrm{MPa}$ confinement pressure. There was a rupture at $2 \mathrm{~cm}$ above the O-ring and significant deformations around the external asperities of the sample. On the other hand, the neoprene membrane resisted a confining pressure of $50 \mathrm{MPa}$ but attenuates significantly more than $55 \%$ of the neutron beam on NeXT because of the high hydrogen content ( Note that this membrane attenuates more than a cylindrical dry concrete sample of $7 \mathrm{~cm}$ diameter!). Teflon membranes of 2 -mm thickness were found to be the optimal compromise, given their comparatively low neutron attenuation, good mechanical resistance and flexibility. Furthermore, these Teflon membranes are reusable and do not require their internal diameter to be within one millimetre of the sample's external diameter, which is instead a strong limitation of the aluminium 
membrane. Especially when using concrete, the control of the sample dimensions with one millimetre accuracy is cumbersome to ensure since some shrinkage phenomena necessarily take place during hardening and thus the external dimensions can slightly change during time.

\subsection{Hydraulic equipment}

Two high-pressure fluid pumps are needed to operate the cell: one to impose the confining pressure and the other for the driving pressure. During the test, two syringe pumps with accurate flow rates were used. These pumps were pressure-controlled. The pump used to maintain the confining pressure is a Sanchez VPSSH 6/700 and can reach a pressure of $70 \mathrm{MPa}$ and has a small reservoir of $6 \mathrm{~cm}^{3}$. The injection pump is an ultra-high pressure Cetoni neMESYS XL 7000N that offers a number of different reservoirs which can be remotely refilled with valve control. With the $10 \mathrm{~cm}^{3}$ reservoir used in this work, a pressure of $89 \mathrm{MPa}$ can be reached. High-pressure tubes are used in order to ensure the connection between the pumps and the cell. Each pump should be connected to a valve in order to stop the injection (to do a tomography for example) or disconnect the confinement when necessary. A flow meter is required at the outlet of the cell to measure the exit flow.

\subsection{Outline of the neutron facility}

\begin{tabular}{|c|c|}
\hline Neutron flux $\left(\mathrm{cm}^{-2} \mathrm{~s}^{-1} \mathrm{~mA}^{-1}\right)$ & $1 \times 10^{8}$ for an $\mathrm{L} / \mathrm{D}$ of 660 \\
\hline Mean energy of neutrons $(\mathrm{meV})$ & 12.3 \\
\hline Collimation ratio used $(\mathrm{L} / \mathrm{D})$ & 660 \\
\hline Scintillator & ${ }^{6} \mathrm{LiF} / \mathrm{ZnS} 100 \mu \mathrm{m}$ \\
\hline Maximum diameter of neutron beam $(\mathrm{mm})$ & 240 \\
\hline Camera & Hamamatsu Orca 4.0V2 \\
\hline Lens & Canon $50 \mathrm{~mm} \mathrm{f} / 1.4$ \\
\hline Image size (pixel, 16 bit) & $1024 \times 1024($ binning 2$)$ \\
\hline Exposure time for one image in the experiment $(\mathrm{s})$ & 10 \\
\hline Pixel Size $(\mu \mathrm{m} /$ pixel) in the experiment & 100 \\
\hline
\end{tabular}

Table 3. Characteristics of the neutron beam facility used in this project.

The preliminary test presented in this article was performed at the newly developed NeXT instrument at the Institut Laue Langevin (ILL) at Grenoble-France (https://next-grenoble.fr/). ${ }^{14}$ The ILL is the world's most powerful neutron source with $1.5 \times 10^{15}$ thermal neutrons per second per $\mathrm{cm}^{2}\left(\mathrm{n} / \mathrm{s} / \mathrm{cm}^{2}\right)$ and a mean neutron energy of $12.3 \mathrm{meV}$. This novel instrument, which at the time of this writing is still under development, currently allows for tomographies down to 30 microns resolution (and is expected to achieve soon a resolution of 10 microns) and has field of view up to $170 \times 170 \mathrm{~mm}^{2}$. The collimation length is about $10 \mathrm{~m}$ and the pinhole (D) ranges between $1.5 \mathrm{~mm}$ and at the time of the test $15 \mathrm{~mm}$, although the radiation protection has recently been upgraded to allow pinholes up to $30 \mathrm{~mm}$. The neutron flux at the instrument, for a collimation ratio of $\mathrm{L} / \mathrm{D}=660$, is about $1 \times 10^{8} \mathrm{n} / \mathrm{s} / \mathrm{cm}^{2}$. Table 3 shows the characteristics of the neutron radiography facility used in this project.

\section{EXPERIMENTAL METHOD}

The experimental procedure is sketched in Figure 5. The following steps are required to prepare and execute a permeability test with in-situ neutron scanning:

- A neutron and x-ray tomography of the sample before starting the test is recommended in order to know its initial state and the distribution of aggregates and pores.

- The sample should be saturated with heavy water (if local permeability in the sense of Darcy's Law is to be calculated later 1). Heavy water $\mathrm{D}_{2} \mathrm{O}$ is selected as the ideal initial pore fluid because its significantly lower neutron attenuation ( 7 times less than the normal water $\mathrm{H}_{2} \mathrm{O}^{15}$ ) simplifies the imaging of the initial state and microstructure of the sample. 
- The sample is set on the base of the Hassler cell and covered with the membrane before closing the cell hermetically $\mathbf{2 , 3}$ (See section 3.1).

- The system of pumps, cables, valves and flow meter is then connected and set as indicated 4 .

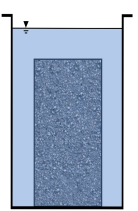

$-1-$

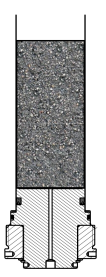

$-2-$

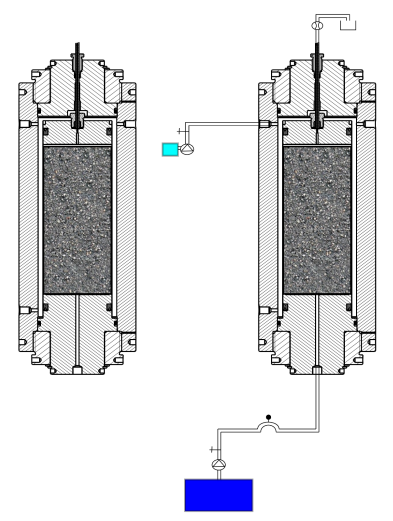

$-3-$

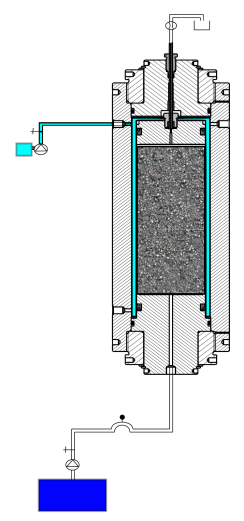

$-5-$

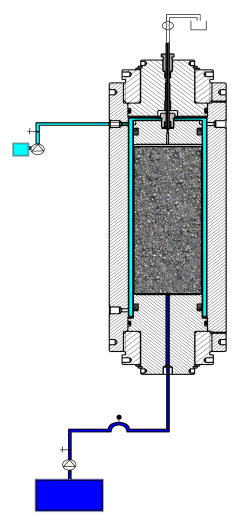

$-6-$

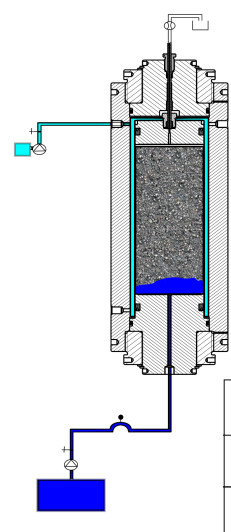

$-7-$

\begin{tabular}{|c|c|}
\hline$\oslash$ & Flow Meter \\
\hline$\otimes$ & Pump \\
\hline$\dagger$ & Valve \\
\hline$\square$ & $\mathrm{H}_{2} \mathrm{O}$ supply \\
\hline$\square$ & $\mathrm{D}_{2} \mathrm{O}$ supply \\
\hline
\end{tabular}

Figure 5. Experimental approach of the experiment.

- The confinement chamber is filled with heavy water $\mathbf{5}$ and air is expelled from the system by pushing the water until bubbles stop appearing from the exit nozzles.

- Confining pressure is slowly increased until the desired confinement is achieved.

- The pressure in the injection pump is slowly increased until the desired hydraulic head is achieved, injecting normal water under constant pressure while monitoring the outflow using the flow meter $\mathbf{6 , 7}$.

- While injecting, neutron radiographies can be acquired in order to measure the advancement of the normal water front due to the contrast between $\mathrm{H}_{2} \mathrm{O}$ and $\mathrm{D}_{2} \mathrm{O}$. Since this technique only provides a projection of the sample, it allows for fast acquisitions, so that it is possible to follow the front "live".

- It is possible to stop the injection, which allows for the stable conditions necessary to acquire tomographies while maintaining the same confining pressure. These tomographies provide extra informations than the radiographies about the shape of the $3 \mathrm{D}$ front in the sample.

- By assessing the rising front in the sample, a speed map can be obtained. A speed map can be used as input to advanced inverse analysis techniques to yield a permeability field.

It should be noted that neutron images are normalised by the "dark" and "flat" calibration images (standard practice), and artefacts from gamma radiation are detected and removed from radiography by using a "remove outliers" procedure.

\section{PRELIMINARY TEST}

In this section we present a representative test performed with the proposed setup to clarify the potential of the cell and highlight some key findings enabled by the use of the cell. A standard cylindrical concrete sample of 7 $\mathrm{cm}$ in diameter and $7 \mathrm{~cm}$ in height was selected to contain sufficient aggregates to be representative, and was cast and kept saturated with heavy water. A tomography of the sample in its membrane was taken before mounting it in the cell. This tomography was acquired by taking 5034 radiographies ( 3 projections per position) of 2 sec 


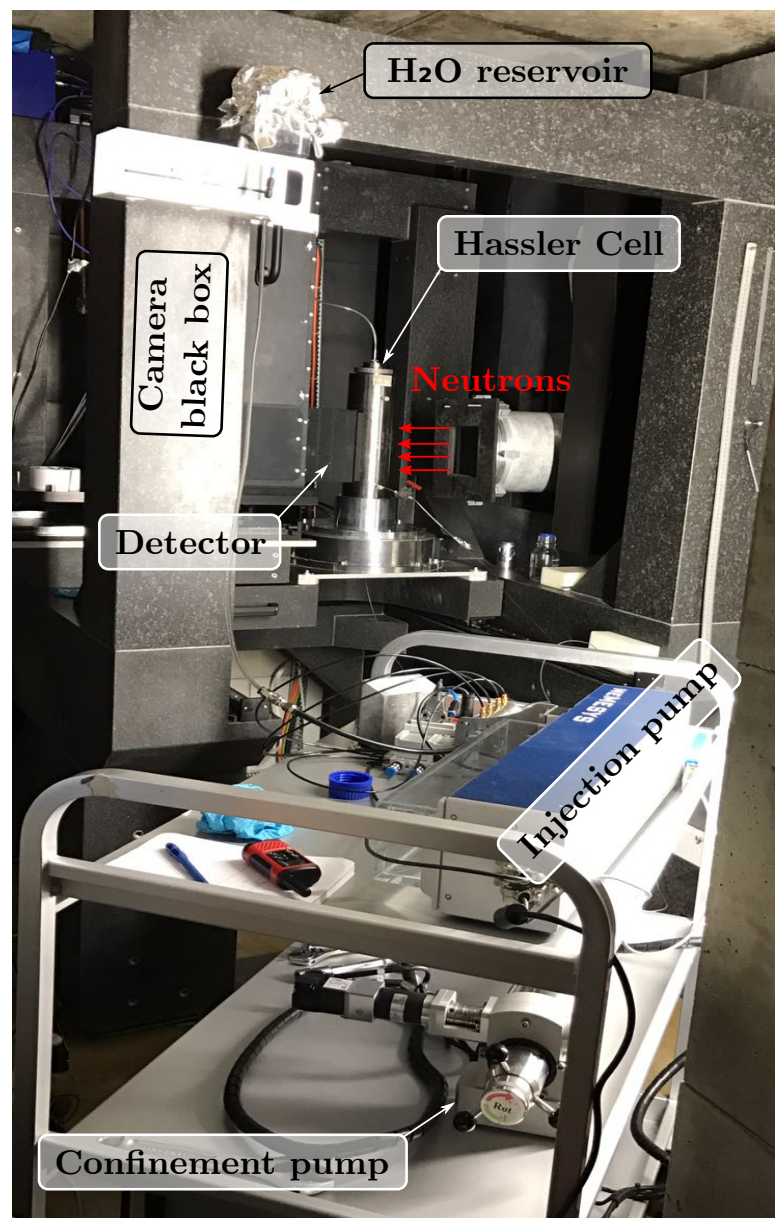

Figure 6. Experimental set-up at the NeXT-Grenoble beamline on D50 at the ILL.

exposure with no binning ${ }^{\ddagger}$ (images of 2048 x 2048 pixels) over 360 degrees. Figure 7 shows the attenuation of the saturated $\mathrm{D}_{2} \mathrm{O}$ concrete sample inside the membrane. In the image it is clear that there is a highly neutron-attenuation region, corresponding to a film of heavy water interfacing the two, which was added to avoid evaporation and to keep the sample saturated while the test is performed. It is presumed that this water is pushed outside the sample when the confining pressure forces the membrane in contact with the sample in order to seal it well.

The porosity is greater at the surface because of the wall effect in the molding of a granular medium. This porosity is probably full of heavy water that attenuates more. As we can see the sample was not fully saturated (the light zones correspond in fact with air-filled pores) since it was kept under water for one month before the test without performing vacuum water saturation methods.

The flow experiment set-up detailed in section 4 was prepared, as shown in Figure 6, at which point the test was performed. During the test, the confining pump was filled with $\mathrm{D}_{2} \mathrm{O}$ and the pressure was set at $30 \mathrm{MPa}$. On the other hand, the injection pump was saturated with $\mathrm{H}_{2} \mathrm{O}$ and refilled remotely during the experiment thanks to an $\mathrm{H}_{2} \mathrm{O}$ reservoir. After a stable confinement was achieved, $\mathrm{H}_{2} \mathrm{O}$ was injected at 20 MPa. This pressure was optimised based on the speed of the imaging instrument and the available beamtime. The neutron beam was

$\ddagger$ Binning is the procedure of merging a cluster of pixels into a single pixel. As such, in a binning 2 , an array of 4 pixels becomes a single larger pixel which reduce the overall number of pixels. In our case, using binning 2 images leads to images of 1024 x 1024 pixels. Binning reduces noise (at the cost of a doubled pixel size). Reading the camera directly in a binned mode may also reduce the impact of readout noise. 


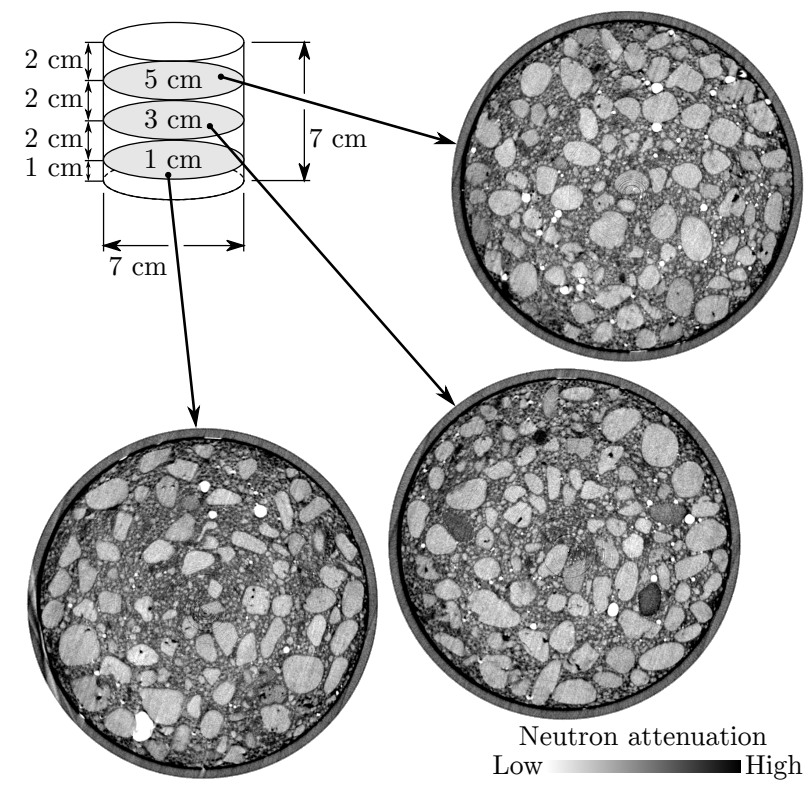

Figure 7. Horizontal slices of the reconstructed 3D tomography of the heavy water saturated concrete sample within its Teflon membrane before the beginning of the normal water injection in different positions of the sample $(1 \mathrm{~cm}, 3 \mathrm{~cm}$ and $5 \mathrm{~cm})$.

oriented by a collimator before it interacts through the cell and the sample. The transmitted neutrons are then converted into visible light by a scintillator screen. The light emitted is deflected by the mirror and recorded by the camera.

During the water percolation process, a series of radiographies with an exposure time of 10 seconds were acquired through the injection phase, which lasted around $1 \mathrm{hr} 40 \mathrm{mins}$. The neutron exposure time has been increased to compensate for the attenuation of the cell and confining fluid. Periodically the injection was paused to acquire longer neutron-tomographies in order to characterize the $\mathrm{H}_{2} \mathrm{O}$ front in 3D. 2-hour tomographies were launched during the experiment. 720 projections were acquired, each the result of the average of 3 projections, over an 180 degrees rotation (see section 6). The exposure time was also 10 secs and the images were acquired with binning 2. It should be noted that the chosen number of projections is an optimisation between the time of the test and the resolution/quality of the image.

\section{RESULTS}

Figure 8 shows the neutron radiographies of the normal water flow (blue - high attenuation) into the concrete sample saturated with heavy water (green - low attenuation) during the injection test.

A series of horizontal sections of the 3D tomography acquired after 39 min of $\mathrm{H}_{2} \mathrm{O}$ injection is shown in Figure 9, the distance between two slices being of about $1 \mathrm{~cm}$ in the sample. It can therein be observed that the normal water is flowing more pronouncedly in the left part of the sample. Figure 8 shows that the water percolates directly in the higher porosity zones of the concrete, notably in the large pore visible at $1 \mathrm{~cm}$ from the bottom which was observed to rapidly fill. 
Time-resolved neutron radiographies

(averaged over $11 \mathrm{~min}$ )
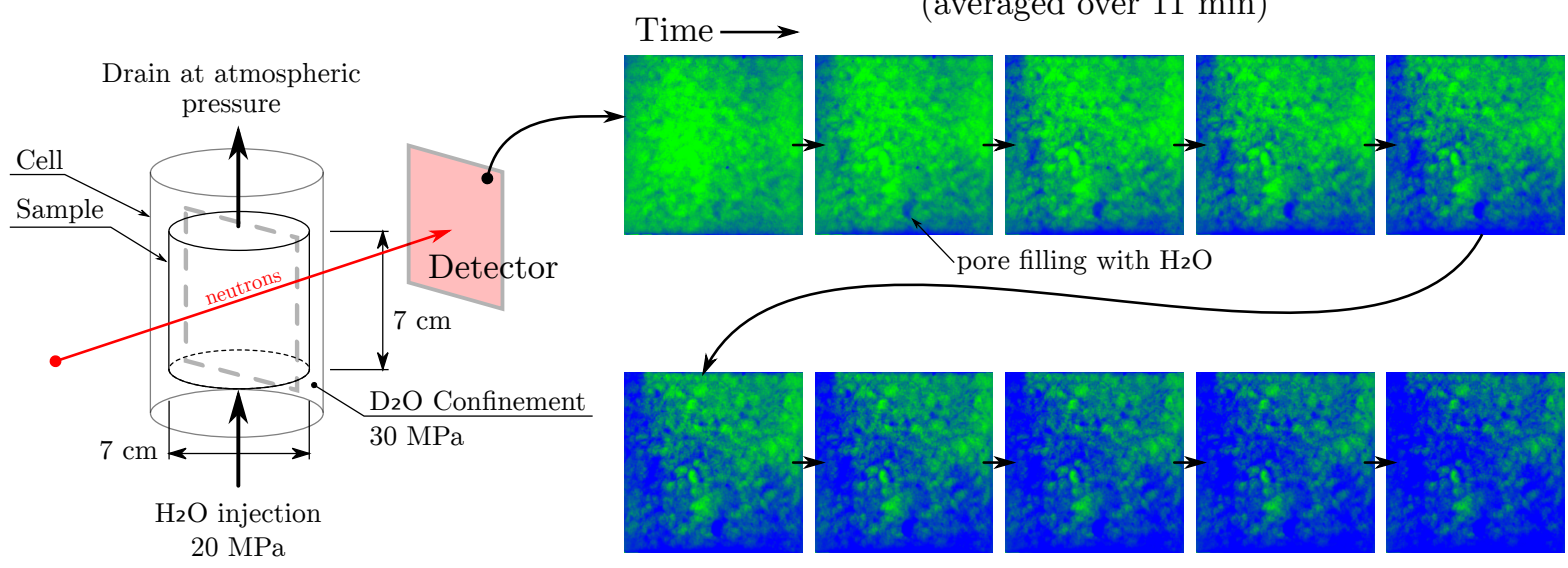

Neutron attenuation $3 \% \quad 6 \%$

Figure 8. Time-lapse neutron radiography images of normal water injection into heavy water concrete sample. Radiographies are averaged over 11 minutes. Neutron attenuation is the raw attenuation measured net of cell, confining fluid and membrane.

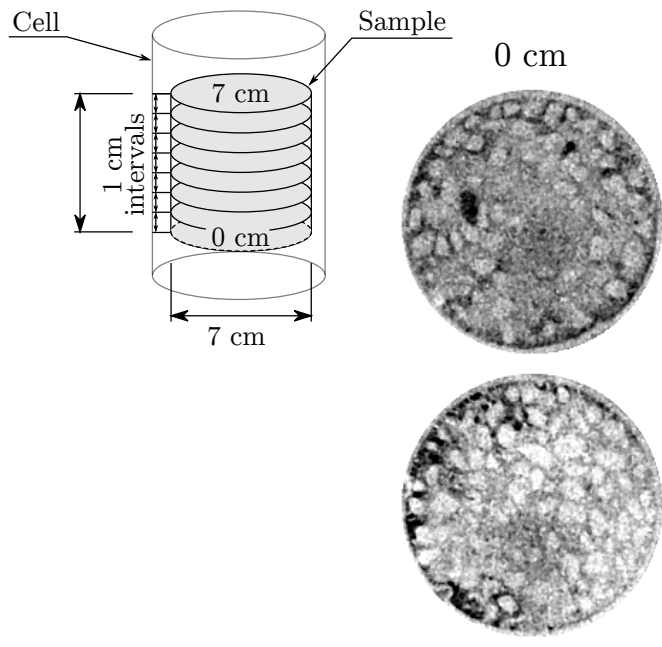

$4 \mathrm{~cm}$
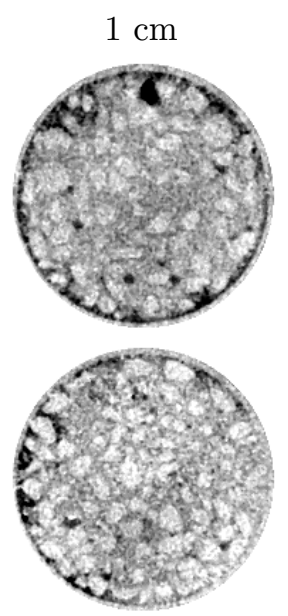

$5 \mathrm{~cm}$

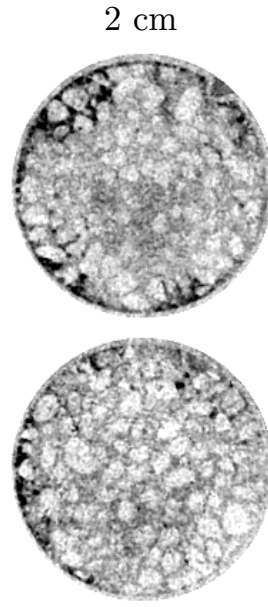

$6 \mathrm{~cm}$

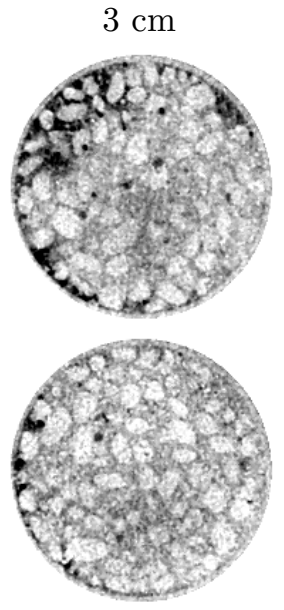

$7 \mathrm{~cm}$

Neutron attenuation
Low

Figure 9. Series of horizontal slices showing the distribution of the water in the different positions of the sample after 39 minutes of injection.

\section{CONCLUSION}

This contribution presents a new experimental method and preliminary results from neutron imaging under the high pressures required to impose significant fluid flows in low permeability media, taking advantage of the high contrast between the normal water flushed in the sample and the heavy water used to saturate it. The key aim of the work was to follow a rising front in the saturated specimen under high pressure, which provides the possibility to acquire a velocity field and therefore to estimate a local permeability field by inverse analysis in the future. In this paper we presented the design of the titanium Hassler cell that allows for studying large samples with a very low permeability since high pressure can be used. The methodology and the experimental set-up used to study the driving fluid flow within the porous media by neutron imaging was presented. The 
test performed on concrete showed that the front is not homogeneous contrary to expectations, which opens the door to many questions concerning the transfer of properties in concrete and the key role played by the porosity. This study is a proof of concept opening new venues due to the combination of high neutron flux instruments allowing tests to be performed on low-permeability materials in reasonable time.

\section{ACKNOWLEDGMENTS}

We would like to thank Erika Tudisco for the suggestion of Teflon membranes. This work was supported by EDFSEPTEN/DTG/CIH within the Chair PERENITI agreement with the Grenoble INP Partnership Foundation. The Chair PERENITI partners shall not in any circumstances be deemed liable for the content of this publication which is only binding its author. The Laboratoire 3SR is part of the LabEx Tec 21 (Investissements d'AvenirGrant agreement $n^{\circ}$ ANR -11-LABX-0030).

\section{REFERENCES}

[1] M. Choinska, A. Khelidj, G. Chatzigeorgiou \& G. Pijaudier-Cabot (2007). Effects and interactions of temperature and stress-level related damage on permeability of concrete. Cement and Concrete Research, 37, 79-88.

[2] L. Alarcon-Ruiz, M. Brocato, S. Dal Pont \& A. Feraille (2010). Size effect in concrete intrinsic permeability measurements. Transport in Porous Media, 85(2), 541564.

[3] V. Picandet, A. Khelidj \& B. Hervé (2009). Crack effects on gas and water permeability of concretes. Cement and Concrete research, 39(6), 537-547.

[4] H. Loosveldt, Z. Lafhaj \& F. Skoczylas (2002). Experimental study of gas and liquid permeability of a mortar. Cement and Concrete research, 32(9), 1357-1363.

[5] D. Huo \& S.M. Benson (2016). Experimental investigation of stress-dependency of relative permeability in rock fractures. Transport in Porous Media, 113(3), 567590.

[6] F.C. De Beer \& M.F. Middleton (2006). Neutron radiography, porosity and permeability in porous rocks, South African Journal of Geology, 109, 541-550.

[7] S.A. Hall (2013). Characterization of fluid flow in a shear band in porous rock using neutron radiography. Geophysical Research Letters, 40(11), 2613-2618.

[8] F.C. De Beer, J.J. Le Roux \& E.P. Kearsley (2005). Testing the durability of concrete with neutron radiography. Nuclear Instruments and Methods in Physics Research, Section A: Accelerators, Spectrometers, Detectors and Associated Equipment, 542(1), 226-231.

[9] M. Kanematsu, I. Maruyama, T. Noguchi, H. Iikura \& N. Tsuchiya (2009). Quantification of water penetration into concrete through cracks by neutron radiography. Nuclear Instruments and Methods in Physics Research, Section A: Accelerators, Spectrometers, Detectors and Associated Equipment, 605(1-2), 154-158.

[10] P. Zhang, F.H. Wittman, T. Zhao \& E.H. Lehmann (2010). Neutron imaging of water penetration into cracked steel reinforced concrete. Nuclear Engineering and Design, 241, 4758-4766.

[11] P. Zhang, F.H. Wittmann, T.J. Zhao, E.H. Lehmann \& P. Vontobel (2011). Neutron radiography, a powerful method to determine time-dependent moisture distributions in concrete. Nuclear Engineering and Design, 241(12), 4758-4766.

[12] S. Lal, L.D. Poulikakos, M. Sedighi Gilani, I. Jerjen, P. Vontobel, M.N. Partl, J.C. Carmellet \& D. Derome (2014). Investigation of water uptake in porous asphalt concrete using neutron radiography. Transport in Porous Media, 105(2), 431-450.

[13] US Army COE (1992). Test Method for Water Permeability of Concrete Using Triaxial Cell. US Army Corps of Engineers Standard CRD-C163-92

[14] A. Tengattini, D. Atkins, B. Giroud, E. Andò, J. Beaucour, G. Viggiani (2017). "NeXT-Grenoble, a novel facility for Neutron and X-ray Tomography in Grenoble". Proceedings ICTMS2017

[15] E. Perfect, C.-L. Cheng, M. Kang, H.Z. Bilheux, J.M. Lamanna, M.J. Gragg \& D.M. Wright (2014). Neutron imaging of hydrogen-rich fluids in geomaterials and engineered porous media: A review. EarthScience Reviews, 129, 120-135. 
[16] J. Murison, R. Moosavi, M. Schulz, B. Schillinger \& M. Schröter (2015). Neutron tomography as a tool to study immiscible fluids in porous media without Chemical dopants. Energy \& Fuels, 10, 6271-6276.

[17] C. Poinard, E. Piotrowska, Y. Malecot, L. Daudeville \& E.N. Landis (2012). Compression triaxial behavior of concrete: The role of the mesostructure by analysis of X-ray tomographic images. European Journal of Environmental and Civil Engineering, 16, 115-136.

[18] E. Perfect, C-L. Cheng, \& P. Lehmann (2011). Neutron imaging and applications: A reference for the imaging community. Vadose Zone Journal, 10, 1336-1337.

[19] E. Stavropoulou, E. And, A. Tengattini, M. Briffaut, F. Dufour, D. Atkins, G. Armand (2018). Liquid water uptake in unconfined Callovo Oxfordian clay-rock studied with neutron and x-ray imaging. Acta Geotechnica (accepted for publication) 